\title{
Children must be protected from the tobacco industry's marketing tactics
}

\author{
Nicholas Hopkinson chair ${ }^{1}$, Colin Wallis chair ${ }^{2}$, Bernard Higgins chair ${ }^{3}$, Stephen Gaduzo chair ${ }^{4}$, \\ Rebecca Sherrington chair ${ }^{5}$, Sarah Keilty honorary president ${ }^{6}$, On behalf of Myra Stern, John Britton, \\ Andrew Bush, John Moxham, Karl Sylvester, and 451 others
}

${ }^{1}$ British Thoracic Society Chronic Obstructive Pulmonary Disease Specialist Advisory Group, National Heart and Lung Institute, Imperial College, London SW3 6NP, UK; ' ${ }^{2}$ British Paediatric Respiratory Society, Great Ormond St Hospital, London, UK; ${ }^{3}$ British Thoracic Society, Freeman Hospital, Newcastle on Tyne, UK; ${ }^{4}$ Primary Care Respiratory Society, Cheadle Medical Practice, Stockport, UK; ${ }^{5}$ Association of Respiratory Nurse Specialists, Princess Elizabeth Hospital, Guernsey; ${ }^{6}$ Association of Chartered Physiotherapists in Respiratory Care, Guy's and St Thomas' NHS Foundation Trust, London, UK

Every day in the UK, hundreds of children aged $11-15$ years start smoking for the first time, ${ }^{12}$ and there is compelling evidence that children's perceptions of cigarettes are influenced by branding. ${ }^{34}$ As health professionals working to prevent and treat lung disease caused by smoking, we welcome the government's decision to enable legislation for standardised packaging of cigarettes in an amendment to the Children and Families Bill.

Industry documents make it clear that after the prohibition of tobacco advertising, promotion, and sponsorship cigarette packaging became the tobacco industry's key marketing tool to attract and retain customers. Current tobacco packaging makes cigarettes and smoking appear appealing and distracts attention from health warnings. Packaging also misleads consumers about the harmfulness of products. Although terms like "light" and "mild" have been banned, smokers still perceive lighter coloured packs to be less hazardous.

Standardised packaging will include requirements that packs are a standard drab colour and have large graphic health warnings on the front and back. Security features, including number codes and covert anti-counterfeit marks that can be read by scanners, will be retained, so it will be no easier to counterfeit products, despite claims to the contrary from the tobacco industry.

Most smokers start before the age of 18 and the younger the age at which they start the greater the health risk. There is no time to lose, and parliament must act now to protect children from the marketing tactics of the tobacco industry.

\section{Competing interests: None declared.}

Full list of authors at: www.bmj.com/content/347/bmj.f4493/rr/674973.

1 Gulland A. WHO urges complete ban on tobacco marketing. BMJ 2013;347:f4493. (11 July.)

2 Hopkinson NS, Lester-George A, Ormiston-Smith N, Cox A, Arnott D. Child uptake of smoking by area across the UK. Thorax 2013; published online 4 Dec. doi:10.1136/ thoraxjnl-2013-204379.

3 Germain D, Wakefield MA, Durkin SJ. Adolescents' perceptions of cigarette brand image: does plain packaging make a difference? J Adolesc Health 2010;46:385-92.

4 Morgenstern M, Poelen EAP, Scholte R, Karlsdottir S, Jonsson SH, Mathis F, et al. Smoking in movies and adolescent smoking: cross-cultural study in six European countries. Thorax 2011; doi:10.1136/thoraxjnl-2011-200489.

Cite this as: BMJ 2013;347:f7358

๑ $\odot$ BMJ Publishing Group Ltd 2013 